\title{
Front End Planning Tool (FEPT) Based on an Electronic Process Management
}

\author{
Mahdi Safa ${ }^{1}$, Carl T. Haas ${ }^{2}$, Keith W. Hipel ${ }^{3}$, and Joel Gray ${ }^{4}$
}

\begin{abstract}
Research indicates that good front-end planning (FEP) results in the achievement of higher levels of project performance. By facilitating collaboration among stakeholders in diverse locations with the use of workflow-enabled processes, such pressures can be reduced, and the overall process and results of FEP can be improved. With these goals, a front-end planning tool (FEPT) has been developed as support for owners and major contractors who are engaged in front-end planning. This paper presents the new FEPT and describes how it has been used for construction megaprojects in the nuclear power, oil and gas, and mining industries. The paper begins with the definitions related to and an explanation of the general process for implementing and applying the FEPT and then describes and analyzes how the FEPT was applied in case study projects in order to test its validity. The results indicate that the FEPT increases the efficiency and effectiveness of front-end planning for the megaprojects studied and that it has the potential to produce similar results for other megaprojects.
\end{abstract}

\section{Keywords: front-end planning, supply chain, document management, workflow}

\section{INTRODUCTION}

A construction project can be defined as a sequential activity that relies heavily on detailed planning and programming [1]. In most cases, long-term strategies for a new construction megaproject are established during front-end planning (FEP), which is influenced by a number of constraints, such as resource limitations, government regulations, and environmental restrictions. In construction, the strategic planning process is associated with feasibility studies, sets of priorities, and timing considerations for the initiation of all of the activities that will enable the overall objectives of the project to be met. This process may sound straightforward, but the research shows that many companies have overlooked the important aspect of aligning project performance with their strategic plans $[2,3,4,5,6]$.

A study conducted by the City of Edmonton in which more than 200 capital construction projects were examined with respect to estimation accuracy revealed that only a small portion of projects actually fall within the desirable range of accuracy. The statistics related to cost and schedule overruns clearly indicate a general inability to accurately plan and estimate [7].

The task of planning, prioritizing, and allocating funds is complex $[8,9]$ and should be performed primarily during the front-end planning phase. This research has attempted to shed light on the question of how the use of a high-level engineering tool can enable project managers to

conduct and manage the front-end planning phase more efficiently.
Research in the area of construction project planning, such as "pre-project planning" [10], "front-end loading" [11], and "front-end planning" [12] has validated the belief that the effort spent on strategic project planning pays off in better project results and performance. The research conducted by the Construction Industry Institute (CII) also confirms that FEP is a key factor in improving project performance [13]. These studies show that construction managed well through a comprehensive strategic plan leads to projects being on schedule; within budget; and most importantly, within safely guidelines and with a minimal impact on the environment. Industry research also demonstrates that projects with rigorous FEP perform more than $10 \%$ better in terms of cost, $7 \%$ better with respect to schedule performance, and $5 \%$ better relative to change orders than projects with little FEP [14].

It is important always to keep in mind that no two FEPs can ever be exactly alike because the construction industry is dominated by one-off projects $[15,16,17]$.

Several constraints create this differentiation among construction projects, such as weather, site conditions, site fabrication, and the availability of resources. Local laws and regulations can also be highly inconsistent and variable [18]. For this reason, care must be taken to ensure that the proposed model is flexible enough for use in most construction projects, given their specific characteristics and constraints, and gaps that exist with respect to its execution. Likewise, the construction FEP has the distinctive requirements compared to other electronic process management systems used in other industries.

\footnotetext{
${ }^{1}$ PhD Candidate, Department of Civil and Environmental Engineering, University of Waterloo, 200 University Avenue West, Waterloo, Ontario, N2L 3G1, Canada, msafa@uwaterloo.ca*

2 Professor , Department of Civil and Environmental Engineering, University of Waterloo, 200 University Avenue West, Waterloo, Ontario, N2L 3G1, Canada, chaas@civmail.uwaterloo.ca

${ }^{3}$ Professor, Department of Systems Design Engineering, University of Waterloo, 200 University Avenue West, Waterloo, Ontario, N2L 3G1,Canada, kwhipel@uwaterloo.ca

${ }^{4}$ Product Manager, Coreworx Inc., 800-22 Frederick St., Kitchener, Ontario, N2H 6M6, Canada, JGray@ coreworx.com
} 
The focal point of the literature review conducted for this research was the definition of FEP. CII defines FEP as "the process of developing sufficient strategic information with which owners can address risk and decide to commit resources to maximize the chance for a successful project" [19]. The focus is on creating a strong, early link between the needs or mission of the business and the strategy, scope, cost, and schedule associated with the project and on maintaining that link so that it is unbroken throughout the project life cycle [12]. Cleland and Ireland (2002) have expanded on this definition by stating that FEP is the process of thinking through and making explicit the goals and strategies required in order to bring a project through its life cycle to a successful conclusion when the project process is an appropriate part of the execution of the project owner's strategies [20]. FEP is also a critical process for revealing any unknowns that might arise during a project. The main deliverable of the FEP phase is an adequate level of design that enables the project team to prepare cost and schedule estimates and to identify risk. Once project funding is approved, the FEP design deliverables become the primary input into the next phases in the project life cycle: procurement and detailed design. FEP gates and other life cycle project phases are shown in Figure 1.

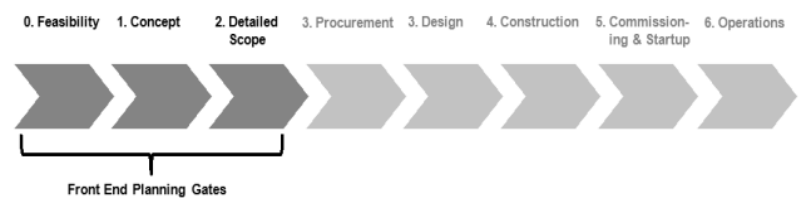

FIGURE I

Front-End PlanNing AND PROJECT LIFE CyCle

The construction industry institute (CII) organized a planning research team whose assignment was to investigate the importance and value of FEP, to assess the resources required to perform the process effectively, and to make a draft of the rules that signify key sub-processes. They found that the FEP process resulted in savings that more than offset the level of investment required in systems, people, and other resources [21]. For capital construction projects (approximately $>\$ 1 \mathrm{~B}$ total installed value), the execution of FEP represents a major effort that involves many thousands of documents and a large team and that cannot be effectively managed through traditional spreadsheets, printed materials, and meeting minutes. Because FEP is a practice involving a diverse set of human interactions, information sources, and integrated processes, companies do not often execute it consistently even when they commit to it. A strong need hence exists for a comprehensive engineering model or tool for conducting this phase. With the goal of applying software technology in order to address the unique characteristics of the planning process and to provide the construction industry with an adequate process management tool to support FEP, the research team comprised of the authors of this paper have developed a software model, designated the front-end planning tool (FEPT), which manages the execution, monitoring, and control of the work activities associated with planning in order to ensure that all deliverables are completed efficiently.

Research also shows that construction companies need to begin educating themselves on new tools and systems to improve the FEP processes. For example, Yu and Lee (2011) investigated and discussed a variety of sets of critical success factors (CSFs) within different aspects of project management information system (PMIS). They also identified CSFs inherent in construction PMIS, and explored their ranking and essential relationship. The result this research could be used as a basis for the research of FEP quality [22].

During the last decade, a revolution has occurred in other industries: business processes have been automated and enforced via the implementation of workflows embedded in corporate and institutional computing systems. Workflows are used most effectively for critical business processes that are subject to time constraints and to scrutiny for compliance with respect to regulated industry processes and human authorization. Examples include human resources management and product support processes. The construction industry is now catching up, and electronic product and process management systems are being developed to enable the implementation of the workflow concept [23]. This research project was initiated as an application of an electronic process management system with the goal of facilitating more efficient and rigorous FEP. The results are presented in this paper. The following three sections, describe the FEPT implementation, identify the main components, and explain the FEPT control system. The application of the tool in three case studies is briefly presented. Based on the three case studies and on ten additional projects, a broader analysis includes the quantification and, in other instances, a qualitative assessment of the impact of the FEPT. The final section presents conclusions, the limitations of the research, and recommendations for future investigation.

\section{FEPT BACKGROUND AND DESCRIPTION}

Defining FEPT requires clarification of the terminology. In a number of industry segments and locales, practitioners have referred to FEPT as a Front End Engineering Design (FEED) tool. A review of the related literature reveals that a number of companies use FEED as a descriptor for a wide variety of planning objectives and define FEED based on the specific objectives of their company. For this study, the term FEPT was therefore selected in order to avoid any confusion with other types of FEED tools.

The FEPT has not been the only practical tool applied for managing FEP processes. A few companies have developed a software model for directing and operating this phase of construction projects. For specialist greenfield projects, Kentz Integrated Solutions (KIS) provides multi-discipline engineering services, including FEED [24]. Tenaska Trailblazer Partners, LLC contracted with Fluor to complete a FEED study for the carbon 
dioxide capture portion of a project [25]. KBR Inc. has been awarded a contract by Saudi Aramco to furnish a FEED system at the Shaybah field. KBR provides FEED for creating the process design and layout, developing equipment and material specifications, preparing bid packages, and estimating construction work with respect to several projects related to the Shaybah NGL Program facilities [26]. A Korean research team supported by the Ministry of Land, Transport and Maritime Affairs of the Korean Government developed the intelligent- program management information systems (i-PgMIS). This system incorporates and integrates some unit modules such as cost-duration management; contract management; risk management; performance management; green VE/LCC, change management, and conflict management which can be used on the FEP phase[27]. Emerson delivers a multidisciplinary approach with FEED, in which the FEED document is the definitive technical and business project summary that includes all of the FEED deliverable documents to be used by the project team. The Emerson FEED involves early design work performed after the conceptual business planning and prior to the detailed design [27]. The Chiyoda FEED, an efficient version that causes few changes during the EPC phase, enhances project performance [28]. Bentley offers a FEED solution that provides the flexibility needed for construction projects while still ensuring interoperability among the multiple software products based on ISO 15926. The Bentley FEED has been helpful for major chemical companies such as Mitsubishi Chemical [29]. None of these models is comprehensive, and they all customarily focus on one or only a few aspects of FEP. While they have contributed significantly to the FEP phase and have satisfied their clients, they are entirely customer- and project-oriented, which means that some were employed only as a module for supporting a specific part of the FEP approach, with the remaining FEP being managed through either traditional approaches or existing partial models. The FEPT, on the other hand, is a very practical tool that conforms to the way experts use it in practice but that has been developed in this research with consideration of all aspects of FEP in order to provide a widely applicable and comprehensive electronic process management system.

It should be noted that while related systems include building information modeling (BIM), integrated construction project management systems, enterprise resource planning (ERP) systems, and generic electronic document management systems (EDMS), an FEPT is unique. It differs from a generic EDMS, because it directly expresses the project delivery mechanism and processes. An FEPT is different from an ERP system, because its instantiation facilitates project mobilization rather than impeding it. Conversely, an FEPT does not functionalize business processes such as accounts receivable and payroll, nor does it manage large databases directly. An FEPT interfaces with business systems such as ERP's, with engineering systems such as CAD, and with project management systems for schedule and cost control. It essentially acts as a meta-manager of these systems.
Recent customer data for Coreworx capital projects shows that most portions of the project costs, the major risks, and the interfaces are defined during the front-end planning. Using the appropriate tools to assist in the making of informed decisions early in the process is therefore critical so that measurable improvements can be realized with respect to the cost, scheduling, and change orders for the overall project. The largest and most challenging deliverable of front-end planning is a level of design sufficient to enable the project team to prepare cost and schedule estimates. While the work involved in drafting the design materials is significant, the process is well understood and is executed by experienced engineering professionals who use established tools. Despite this advantage, the requirements associated with FEP design activities for a major capital project can introduce significant challenges:

- Collaboration between the owner and the engineering contractor(s)

- Hundreds or thousands of design and planning documents transmitted, archived, and indexed for use by a variety of stakeholders who have differing needs

- Timely review and authorized approval of all deliverables

- Full information handover to procurement and detailed design teams at completion

- Little time or budget allocated to the implementation of hardware or software technology to support this process

- Identification and communication requirements with respect to the relationships between scope of work for multiple activities and to the physical and nonphysical interfaces between organizations

\section{- $\quad$ Risk identification and assessment}

For capital construction projects, the engineering contractor produces the design under the supervision of and in consultation with the owner. The parties need to work according to a common plan and structure so that the mountain of documents and correspondence is controlled and accessible to each party. If project funding is approved, the design deliverables from the FEPT become the primary input into the next phases of the project life cycle, which introduces an additional set of information indexing and handover requirements that will make the FEP deliverables useful to procurement or detailed design teams.

With each revision requiring review and approval, the FEP team faces an enormous challenge, given that the FEP schedule spans only a few months from start to finish. The tight schedule typically also makes infeasible many of the options that the FEP team may have considered with respect to software and hardware implementation for managing information and processes. In this research, these challenges led to the development of an information technology model and service as 
support for FEP. The FEPT was thus designed to be an on-demand solution that addresses the specific needs of owners and contractors who are engaged in front-end planning. The FEPT is comprised of a set of services, processes, and access methods for managing planning activities and deliverables (Figure 2).

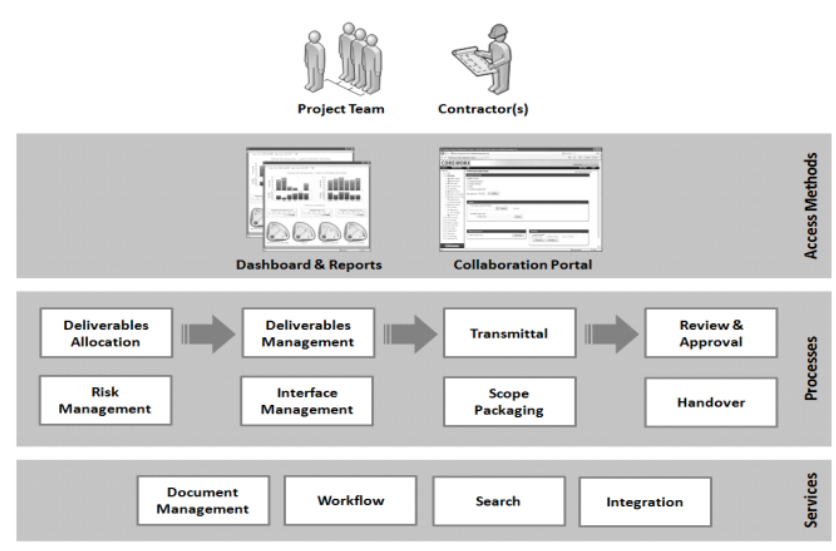

FIGURE II

FEPT COMPONENTS IMPLEMENTED IN THE MODEL

Since all of the activities and deliverables in FEP involve documents, strong document management and search services (bottom row of boxes in Figure 2) facilitate the archiving and retrieval of documents and metadata, along with workflow services that support the process automation requirements. Integration services enable the exchange of data, such as the schedule and the work breakdown structure, with other project systems.

Process features (middle rows of boxes in Figure 2) are critical for efficiently routing information through the activities related to planning. These are the integrated processes implemented using the services described in the preceding paragraph, which link together a series of related activities and shared data so that the planning work can be executed in a consistent, efficient, and predictable manner. User interfaces (top row of boxes in Figure 2) provide easy access that facilitates collaboration between and monitoring of planning activities and deliverables. An example is presented in Figure 3.

In FEP initiatives, the time allocations normally include neither allowances for implementing significant software and hardware infrastructure nor significant budget amounts for information technology (IT) resources. Considering that the life span for the FEPT is the same as for FEP itself, usually no longer than a few months even for the largest projects, the FEPT is provisioned online, also known as "in the cloud," requiring only a web browser and login in order for users to participate. Further details about these components are provided in subsequent sections.

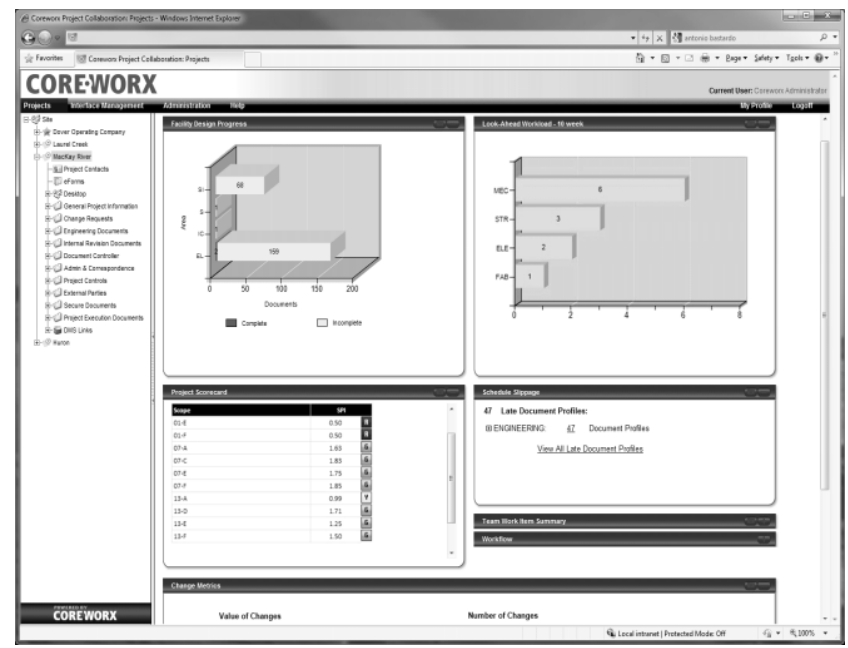

FIGURE III

SAMPLE FEPT USER INTERFACE

\section{FEPT DEVELOPMENT AND IMPLEMENTATION}

The FEP process sets the priorities and timing for initiating a capital construction project in a way that will meet the overall objectives of the owner or main contractor. The FEPT is used to manage three phases of FEP: feasibility, concept, and detailed scope (Figure 1). These phases were described briefly in the introduction but are defined in detail in the next sections, followed by an explanation of the development of the FEPT system. It should be kept in mind that these phases tend to be primarily owner-driven.

\section{A. FEP Phases}

In phase 1 (feasibility analysis), all potential options should be developed and documented. In other words, this phase is a preliminary investigation into the potential options associated with a construction project. These options should then be evaluated against a set of agreedupon criteria. The report resulting from this phase also recommends a course of action and a realistic estimate of the range of the total end costs and life cycle costs of the project. All factors that could affect a desirable outcome, such as the resources available, the time, any outsourcing strategy, the facilities, and any environmental issues, must all be addressed and analyzed.

In phase 2 (concept development), the perception phase, each of the alternatives contained in the feasibility report is analyzed based on mission requirements or business objectives, the scope of a project with respect to fulfilling the mission or objective, and the justification for the project. In other words, once all potential options have been developed and agreed upon by the client, the project team endeavors to create, analyze, optimize, and specify the many aspects of the process parameters, philosophies, and equipment, thereby developing a basic definition of the project. The options identified in the earlier feasibility phase are developed by the project team to a degree of definition that enables project budgets to be accurately assessed and implementation schedules to be set. When 
all the alternatives have been analyzed and the best option determined, the basic project definition, i.e., the concept report, is then completed, in readiness for the next phase.

In Phase 3 (detailed scope development) includes an outline of the main features of a project: the general design, approximate benefits and costs, sources of funding, risk factors involved, the basic organizational structure, interfaces, and a preliminary execution plan (the initial estimate, initial schedule, and safety strategy). In this phase, the definition of the scope of the project is finalized, and the cost/schedule estimate is prepared. Utility requirements are also identified, governmental and environmental restrictions are documented, and an initial site plan is formed. The main output of phase 3 of the FEP consists of a strategic plan for the construction project, which is used as the basis for selecting contractors, defining a work breakdown structure, developing work packaging, identifying work packages and contractor interfaces, considering risk management [31], and beginning the detailed design and other construction project phases.

Lack of a comprehensive strategic plan may lead to a fragmented supply chain approach that creates significant problems [31]. The strategic plan and other reports produced during this phase hence enable the project team to ensure that the project progresses smoothly to the execution phase. The deliverables for this phase include a strategic plan as well as the following:

- Cost estimation and execution strategy in readiness for the final investment

- Risk drivers associated with the project

- Categorical definition of the physical and nonphysical interfaces $(80 \%)$

- Effective reports presented in a ready-to-use format for helping with the selection of the contractors [32]

- Investment cost estimate associated with the corresponding FEPT documentation

- Reports detailing instrumentation, civil, electrical, and piping requirements, for example, a piping and instrumentation diagram (P\&ID)

- Detailed scope of work to be used for defining work packages

Phase 3 represents the majority of the time and deliverables required, so the FEPT developed in this research was designed primarily to address the requirements associated with this phase. An understanding of these phases and of FEP fundamentals was the first step in the development of the FEPT.

\section{B. Front End Planning Tool (FEPT) Development}

The FEPT development for an owner wishing to apply the FEPT to multiple projects consists of a number of processes that take place in sequential order: project characteristics and features analysis, FEPT design, software programming, evaluation, conversion, and proceeding and maintenance $(\mathrm{P} \& \mathrm{M})$. Figure 4 illustrates the sequence of the FEPT development; however, some of the processes may overlap and occur simultaneously.

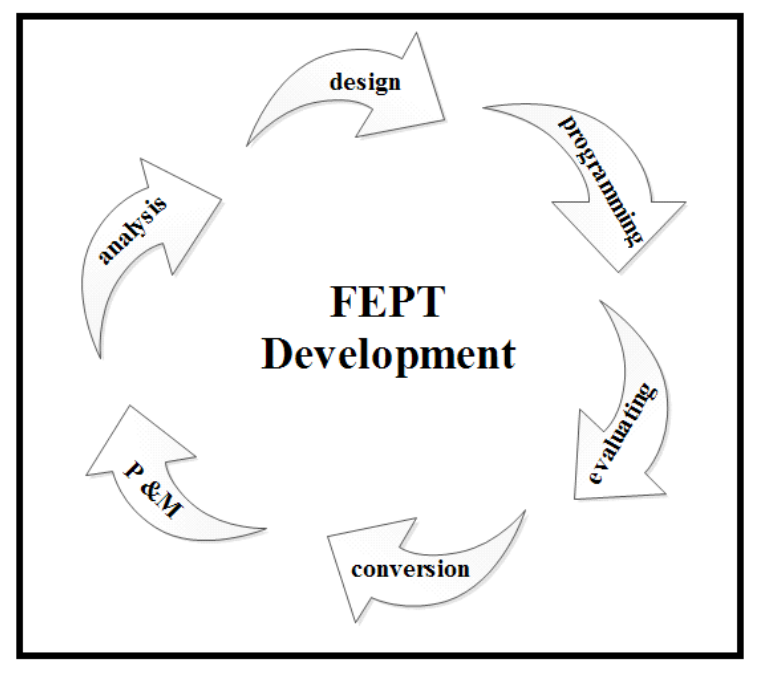

FIGURE IV

FEPT DEVELOPMENT PROCESS

The project analysis determines the level of project performance required by the owner in the planning stage and is therefore expected to help facilitate the decisionmaking process in the FEP phase [33]. It therefore becomes the first step in the process development and leads to the creation of a road map of the existing project systems. FEPT experts, along with the project team, can analyze the project and prepare a framework based on interviews with key project users, an examination of work papers and procedures, and observations of the operation of the existing document system. FEPT experts should also perform a feasibility study in order to determine whether the proposed solution is achievable from technical and financial points of view. Since the FEPT is capable of being customized according to principles established by top management, all alternatives should be evaluated during this phase. To determine the most desirable features, the FEPT should always adhere to the opinions of management and the project team experts with respect to costs, technical features, and system benefits.

Once the project characteristics and features analysis has been performed, the results indicate the action the team must take in order to meet the requirements of the electronic process management system. The FEPT design phase then illustrates how the FEPT can fulfill these requirements. The FEPT experts then detail the project specifications that can deliver the functions identified during the project analysis phase.

The FEPT design then phases into a fully operational electronic process management system, beginning with the transformation of the project specifications and requirements established during the project characteristics and features analysis. The steps in this part of the process 
are comprised of software programming, evaluation, conversion, and review and maintenance.

During the software programming phase, the project specifications are translated into software program code using Oracle software. The automation of the document control functions is performed in this phase and includes metadata population, package creation and integrity checking, version control, approval workflows, exception alerting, and transmittal receipt/generation. Following this step, the FEPT team then develops a test plan to ensure that the system is ready to be used and can be formally accepted. The test plan must be reviewed and evaluated by project experts, management, and end users in order to verify that the proposed model is appropriate for the specific types of application required.

The conversion phase entails transferring information from other systems to the new systems along with all the associated changes required. The conversion phase could be either a pilot or a cutover. In a pilot approach, the FEPT is established for only a limited area of the project, with the remainder of the project still operating with the old methods and systems. The cutover approach involves the complete replacement of the old system with the FEPT.

Once the FEPT is installed and at the beginning of the conversion phase, the FEPT experts and project teams review the system to determine how well it has met the original goals and project requirements, and they then decide whether any reversions or modifications are in order. Maintenance is part of this phase and refers to any necessary changes in the software, the hardware, the producers, or the workflows in order to correct errors and meet new requirements. The amount of maintenance work could obviously be reduced through optimal project characteristics analysis and FEPT design practices. The FEPT offers effective functionality, including collaboration, document control, workflow, and interface management, and other specific modules can be tailored to enable the efficient handling of projects by the project team.

\section{ADVANTAGES AND CHALLENGES}

This section discusses the advantages of the FEPT and the challenges associated with its implementation. The FEPT helps with the management of FEP activities and deliverables with a focus on control and compliance, transparency, and efficiency. These advantages are detailed in the following sections. The adoption of a frontend planning tool sets a high quality standard for information integrity during both FEP and the balance of the project through the application of consistent treatment for every deliverable with regard to (1) archiving and access; (2) naming and numbering; (3) versions; (4) metadata values; and (5) milestone achievements, rules of credit, and the tracking of relations to other information items. The tool enforces governance and compliance with workflow task assignments and sequence and ensures valid authorization for the execution of tasks and for access to reporting information. Each information item is subject to identical processes (e.g., change management approval) and audit history, so authorized users can rely on a single view that incorporates all events and interactions that have affected the information during its full life cycle. If the information managed by the FEPT continues to be used during subsequent project phases, as evidenced with the projects in our case studies, then organizations will benefit from the extended management of information relationships and history.

Front-end planning is characterized by a large volume of documents that must be captured, transmitted, validated, reviewed, and approved. This process has traditionally been accomplished with the use of a mix of printed copies, emailed messages, couriered document packages, and handwritten mark-ups, with spreadsheets to keep track of all of these materials. The FEPT can quickly move electronic versions of this information between participants and stakeholders, and includes verification that correct document versions have been provided, thus reducing the chances of error and the necessity for rework. The FEPT provides electronic design review and mark-up tools that improve the efficiency of the engineering team without the requirement for special software. Workflow timeouts, delegation, and escalation policies function to keep activities on schedule, and the FEPT alerts the appropriate controllers to take action when bottlenecks occur. The entire system is automated and is hosted on servers.

The FEPT helps balance and optimize work and resources. Work items are assigned a relation to the critical path so that each participant prioritizes work according to the requirements of the schedules. The FEPT also applies a project Responsible-AccountableConsulted-Informed (RACI) matrix in order to ensure that the workflow structures automatically direct activities to authorized team members, and that associated reports provide oversight with respect to the appropriate assignment of users to the correct authorized roles and activities. Figure 5 shows a partial RACI matrix, according to which documents are routed based on their discipline and document type. Metadata values and authorization levels are associated with team roles (e.g., approver, reviewer, consolidator, and informed).

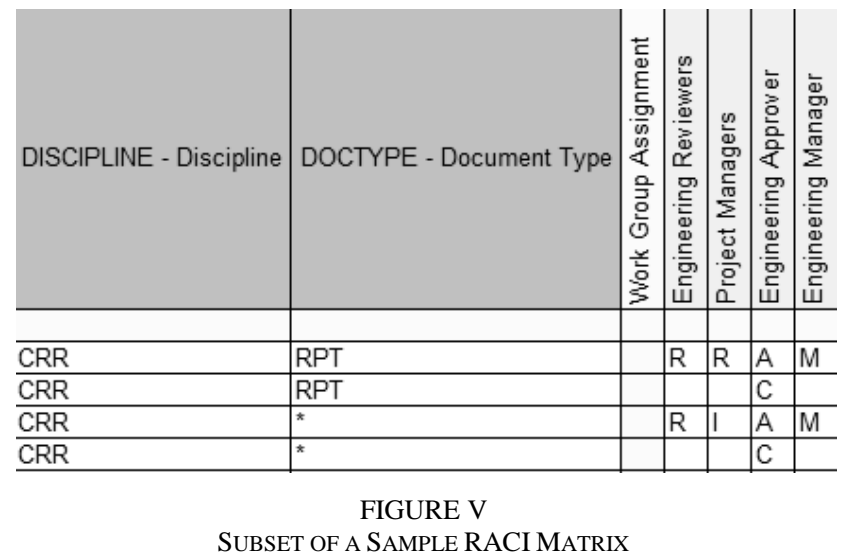

Compressed schedules for front-end planning force the project team to closely monitor progress and performance. The FEPT integrates with the schedule data 
so as to provide performance metrics and also calculates the earned value based on configurable milestones for each work package and its related deliverables. Estimation activities and executive decisions demand that a level of completion be associated with the deliverables before all planning is completed, so the FEPT provides summary and detail reports broken down by scope of work, contractor, information type, or other criteria. Reporting also helps to identity problems as they begin to occur, which enables immediate action and helps measure the impact of actions in real time.

Owners and contractors draw a clear distinction between the planning phases and the execution of the project after it has been approved. This distinction usually includes entirely different teams and partners who use different systems. Project execution teams, such as procurement and engineering, often rely on the data from front-end planning to serve as a baseline for their activities and deliverables. For this reason, the handover of planning data is critical to the success of a project. FEPT enables more efficient assembly of information handover packages, in either hard copy or electronic format, because the details have all been archived electronically during the first three phases of the FEP.

Besides, foregoing advantages there are some challenges associated with the implementation of the FEPT. The lack of communication and the resistance to learning inherent in traditional approaches to the construction industry have a direct effect on the extent to which change is welcomed and new methods are adopted. The main barriers to the implementation of FEPT include but are not limited to the following:

- Schedule constraints: even the largest megaprojects rarely have FEP that extends beyond 24 months, so the time required for implementing and learning a new tool is often prohibitive.

- Budget limitations: FEP budgets are commonly set at $1 \%$ of the total installed value of a project, which may not accommodate the licensing, implementation, and support of the FEPT.

- Contractual terms and methods: Owners and engineering contractors may not agree on the systems and tools required for executing the FEP work.

\section{KEY FEPT FUNCTIONS}

The FEPT has been implemented as an online system that addresses the specific needs of the owners and contractors who manage FEP information deliverables. The FEPT links to the WBS and the baseline schedule from Primavera P6 in order to establish the scope of work and individual work packages. With each work package, the FEPT associates configurable milestone sequences, planned start and finish dates, and planned hours. Each FEP document deliverable is then assigned a weight within a package, along with the planned, actual, and forecast dates for each document milestone. The figure below summarizes the FEPT elements that organize and monitor the schedule with respect to scope, packages, deliverables, and milestones.

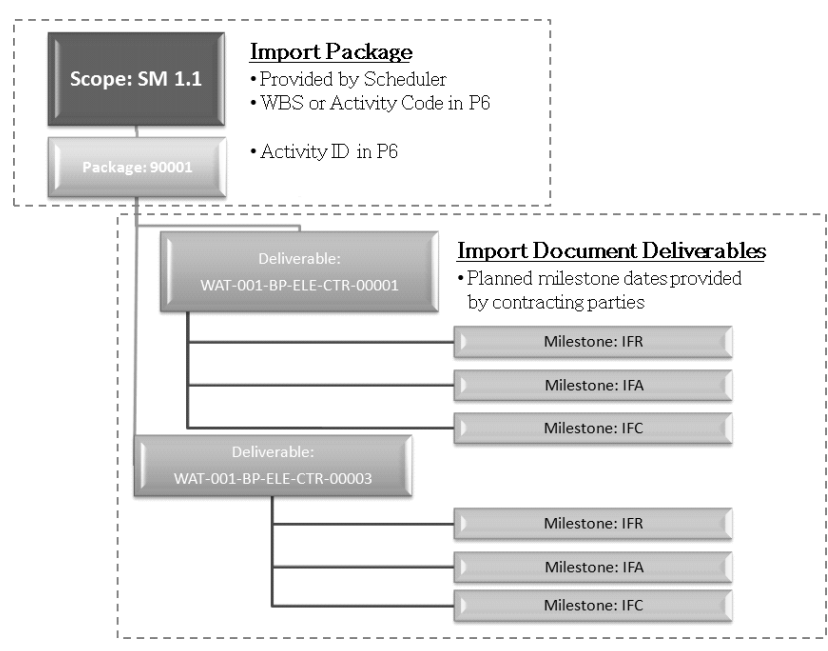

FIGURE VI

FEPT SCOPE, PACKAGES, DELIVERABLES, AND MiLESTONES

With this configuration in place, the FEPT can measure the engineering earned value and schedule performance at each level based on the milestones achieved for the deliverables.

A document management system controls all information associated with the FEP securely and includes features for managing metadata, revisions, relations, and the audit history. With limited time and resources, the FEP team must adopt a proven procedure for projectbased document control. The FEPT includes preconfigured document metadata templates based on ASME standards for design, correspondence, and plan documents.

The FEPT uses a collaboration web site where the FEP team and the design contractors can interact. This site is secure, with user login accounts and permissions that enable each party to quickly access the planning information required for their specific role(s).

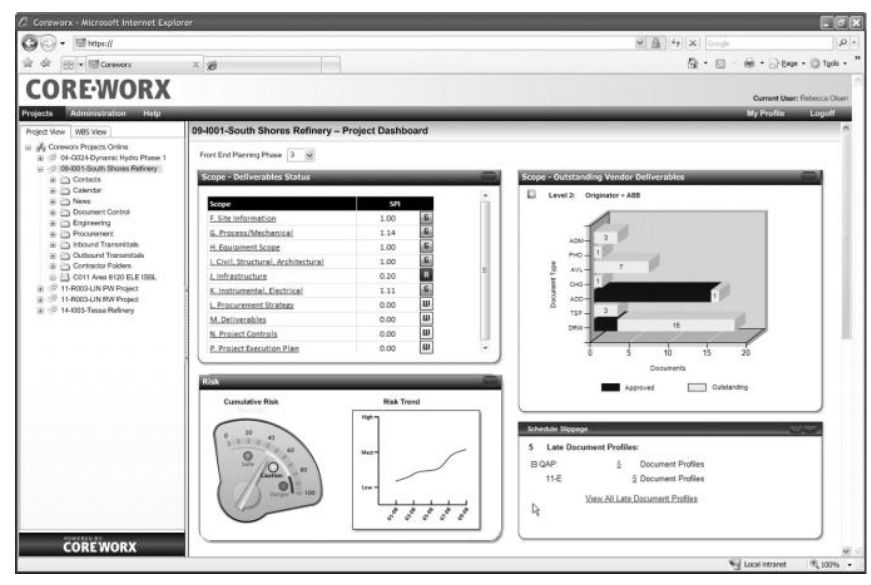

FIGURE VII

FEPT COLLABORATION SITE 
A standardized work process increases the efficiency of the engineering team during the FEP design phase. Using a pre-configured workflow increases the rigor that is applied to the work process of design reviews and equips the engineering team to accurately track the resolution of comments made regarding nonconforming items.

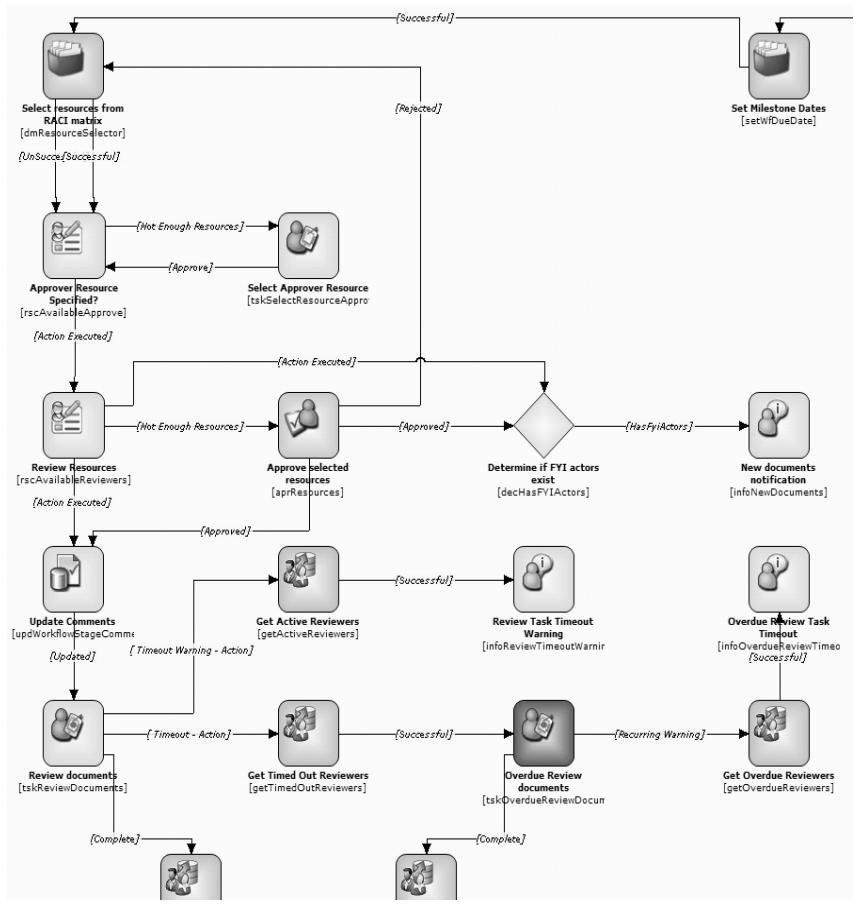

FIGURE VIII

PARTIAl Map OF THE DESIGN REVIEW AND APPROVAL WORKFlow PROCESS

Inbound transmittals provide an automated process for the controlled exchange of documents with verification rules. The transmittal is a zipped (.zip) file that contains both document deliverables and a transmittal cover sheet. The FEP design contractor uploads the transmittal to a pre-configured folder on the collaboration web site. The files are then imported into a controlled archive, which incorporates additional validation in order to ensure that the files and metadata comply with the organization's FEP standards. The FEPT can generate outbound transmittals and send them to the FEP contractor or other stakeholders.

The FEPT includes a change management work process that adds control and visibility to changes in FEP activities and information. All changes must be reviewed and approved by the appropriate authorized individuals. To keep activities and deliverables on schedule, the FEPT provides progress tracking and performance measurement tools. As each document deliverable progresses through its life cycle stages, from allocation to submission to approval and issue, the FEPT automatically triggers milestones, providing the highest level of accurately reported progress. Reports provide real-time visibility for team members and other stakeholders, including calculated progress and performance metrics.

FEP teams and stakeholders use an "FEP Scorecard" (Figure 9) to monitor the overall schedule performance index (SPI) for each scope of work element. The FEPT enables the selection of which scope of work elements (aligned with the WBS codes in the schedule) to include in the scorecard. The SPI is calculated for the scope of work for each work package.

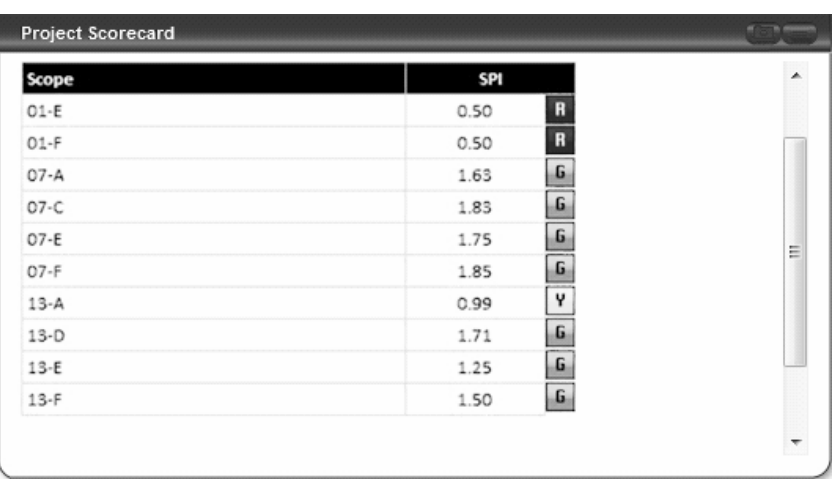

FIGURE IX

FEP SCORECARD

As work progresses and incremental deliverables arrive from the FEP contractors, the FEPT determines what has changed from one submission to another (Figure $10)$.

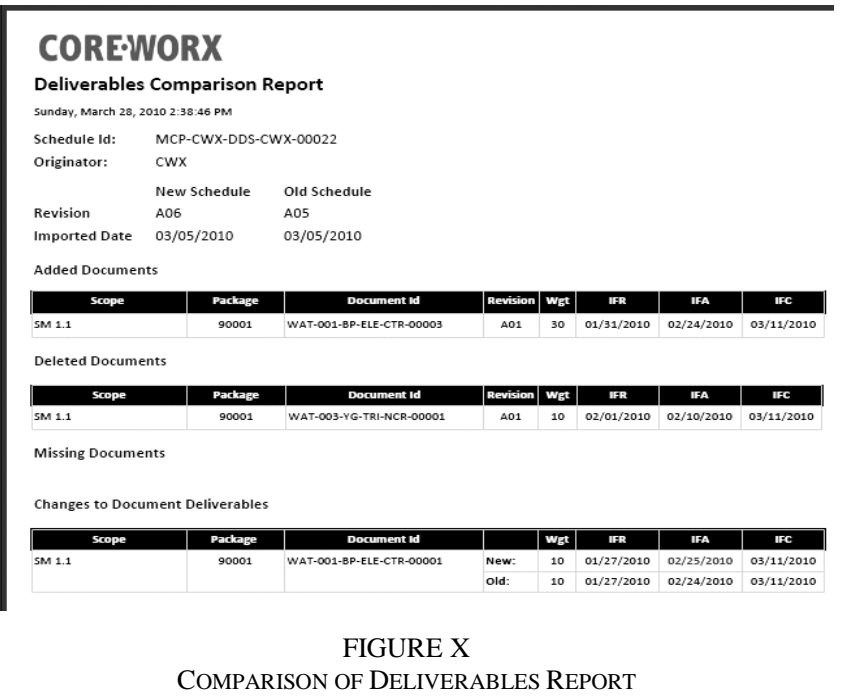

The FEPT also provides a report that identifies any disparities between the delivery dates and the planned dates (Figure 11). 


\section{COREPORX}

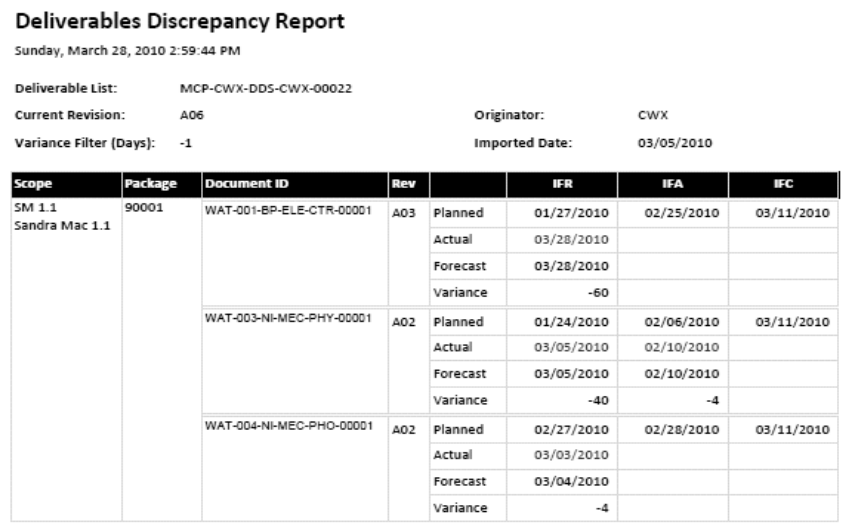

FIGURE XI

DISCREPANCIES IN DELIVERABLES REPORT

The FEPT includes a schedule slippage report for monitoring document deliverables that have either a late start or a late finish (Figure 12). The document details in each package are used as a means of monitoring planned versus actual start and finish dates for each document deliverable.

\begin{tabular}{|c|c|c|}
\hline \multicolumn{3}{|l|}{ Schedule Slippage } \\
\hline \multicolumn{2}{|c|}{58 Late Document Profiles: } & $\hat{\sigma}$ \\
\hline 曰ENGINEERING & $\underline{58}$ Document Profiles & \\
\hline G. & 4 Document Profiles & $\equiv$ \\
\hline $\mathrm{H}$. & 4 Document Profiles & \\
\hline $\mathrm{I}$. & $\underline{50}$ Document Profiles & 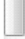 \\
\hline & II Late Document Profiles & - \\
\hline
\end{tabular}

FIGURE XII

SCHEDULE SLIPPAGE REPORT

Managers can use the Team Work Item Summary web page as a tool for quickly identifying overdue and critical path work items assigned to their team members (Figure 13). Details are provided for workflows that are configured for monitoring using this portion of the web site as a function of the FEPT.

\begin{tabular}{|lcccc|}
\hline Team Work Item Summary & & & & \\
\hline Name & Overdue & $\begin{array}{c}\text { Due in 2 } \\
\text { Day(s) }\end{array}$ & High & Active \\
\hline 日 Callum William Wallace & 37 & & 37 & 39 \\
Design Review and Approval & 37 & 37 & 39 \\
$\boxminus$ James Bart Cameron & 35 & 35 & 37 \\
Design Review and Approval & 35 & 35 & 37 \\
& & & & \\
& & & & \\
\end{tabular}

FIGURE XIII

TEAM WORK ITEM SUMMARY REPORT

Managers use the Look-Ahead Workload web page to monitor and balance workloads for all team members. The manager selects a time period (e.g., 2 or 4 weeks) for the look-ahead, and the FEPT provides a summary of the number of documents that a manager's team will work on during that time period, thereby permitting the manager to monitor active and forecasted work.

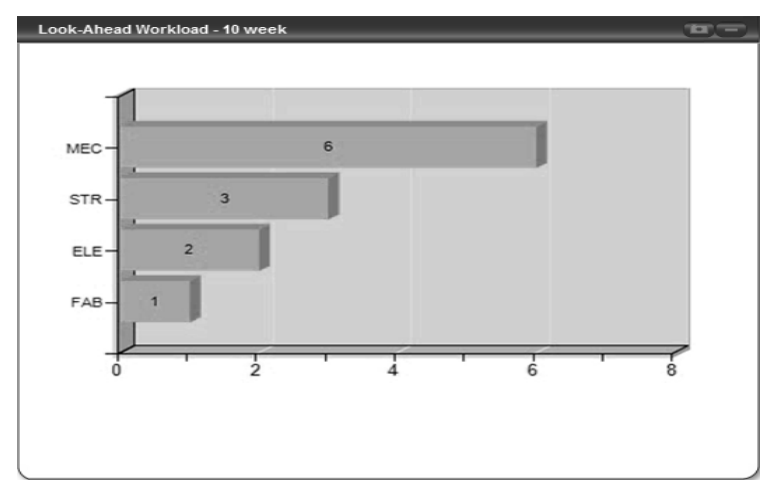

Figure 14: Look-Ahead Workload Report

\section{CASE STUdiES}

The FEPT has been used for major capital projects worldwide that are driven by the need to complete FEP more quickly and to improve the quality of FEP deliverables. This section presents three case studies that were conducted in order to verify the effectiveness of the FEPT. Due to confidentiality restrictions, the actual names of neither the construction companies nor the projects can be included.

\section{A. Case Study 1: Oil Sands - 2010}

This project is located in northern Alberta, Canada. During the planning stage, more than 40 sub-contractors worked directly under the main contractor. The project has a 2020 timeframe, with production expected to reach 200,000 barrels per day once all phases have been built and are operational.

In 2009, the project owner engaged the research and development (R\&D) team to provide an FEPT to support the collaboration and document control needs at the planning stage. A primary requirement was that the FEPT function as part of an integrated project information management system. The integrated system would provide a bridge between the information developed in the FEP stage and the deliverables to be managed during the execution of the project.

The FEPT managed the engineering documents, deliverables (technical and non-technical), and datasheets, excluding loop numbers, piping isometrics, and specialty piping deliverables. The tool enabled the migration (bulk importing) of all pre-allocated engineering deliverables and interfaces and included a work-in-progress area where users of the system could access both a personal work space and shared work spaces. The multiple functional teams utilized several other features: contact lists, links to web pages, shared document areas, news feeds, and forums.

The contractor completed the FEP for Phase 1 of the project and obtained the necessary approvals from the 
Government of Alberta, the Environment Department, and the Energy Resources and Conservation Board (ERCB) so that the project was ready to begin in 2010. The contractor's CEO stated that the overall cost estimate for Phase 1 of the project decreased by almost $\$ 1$ billion during the course of the design optimization, and the project was also set to achieve a solid sustainable economic return based on current market conditions for Phase 1.

\section{B. Case Study 2: Deepwater Gas Field Development - 2010}

This project, a partnership between two major oil companies in North America and Asia, is located in the South China Sea at an average water depth of $1,300 \mathrm{~m}$.

In 2010, the owner partnership signed an agreement specifying the key principles of cooperation for the funding and operation of the deep-water gas field development. The owner partnership and Project Management Contractor (PMC) then awarded lump sum contracts for the scope of three major packages. FEP was completed, and the overall development plan was submitted to regulatory authorities in 2011.

The owner partnership initially intended to use the PMC's systems for FEP, but recognized the inadequacy of these systems. Instead, they wanted a cradle-to-grave application that would record documentation in the planning stage and consistently track and manage it throughout the execution and into the operational phase. Evidence of lost information was the primary driver leading to this decision.

The project employed the FEPT for managing new engineering documents and deliverables (both technical and non-technical) from the three primary EPCs, project correspondence, existing FEP documents, and interface documents. The FEPT facilitated the exchange of information with the contracting parties through the use of its transmittal functionality. Workflows provided control of the review and approval of the deliverables. The vendors were overseen by scope-of-work managers, and administrators granted the parties sufficient access privileges to enable them to exchange information with the project team. It should be noted that 2,800 to 3,500 documents were generated and managed using the FEPT processes.

The FEPT functions were rolled out in controlled phases to enable the initial use of the system as quickly as possible. The FEPT implementation phases were data storage, vendor documents, and enhanced functionality. Phase 1 (data storage) was focused on moving all project data from the legacy project information system into the FEPT, with the goal of making it easier for project team members to find information. This phase included the migration of the most recent version of the documents as well as any project correspondence. Phase 2 (vendor documents) was concentrated on the management of vendor documents, including inbound transmittals, review/approval workflows, and vendor data storage. Phase 3 (enhanced functionality) included the functionality for managing technical queries to and from vendors, interface management agreements, change requests, and enhanced processes for reviewing deliverables through the use of comment sheets and forms.

In 2012, the owner partnership reported that the project was advancing as planned, with the completion of the initial major component and the next significant components scheduled for the second quarter of 2013. The front-end engineering and design work for the development of the next gas field is underway. The development is on target for the first production to occur in late 2013 or early 2014.

\section{Case Study 3: Gladstone Liquefied Natural Gas (GLNG) -2010}

A major North American EPC contractor has utilized the FEPT for dozens of major projects around the globe. This contractor was awarded the Front-End Engineering and Design (FEED) contract for a major portion of the Gladstone Liquefied Natural Gas (GLNG) upstream project, one of the world's largest projects for converting coal-seam gas to liquefied natural gas. The contractor's scope of work for this contract included the preparation of an execution plan and a cost estimate for the engineering, procurement, and construction of the upstream facilities required in order to deliver coal-seam gas from coal-seam gas fields in northeastern Australia to the proposed GLNG liquefaction facility to be located in Gladstone.

The contractor used the FEPT with more than 150 offshore experts from its United States headquarters. The design deliverables of FEED become the primary inputs into the construction phase, when; the project funding was approved. The FEP stage was completed in late 2011.

\section{LESSONS LEARNED}

This section presents the results of the most recent case studies and summarizes the lessons learned from experts and FEPT users. These observations have been derived from the experience with more than 10 projects:

1) For a multi-billion dollar project, a typical duration for FEP is 12 to 24 months. Approximately 100-150 people can be involved at a given point, about 50 of whom are commonly the owner staff, but this rule of thumb should be applied: improve decision making by using enough owner expertise and capacity to challenge what the engineering contractor represents during FEP [34].

2) The goal of FEP is to obtain sanction for the project to move forward as quickly as possible, based on a detailed scope of work, cost estimates, etc. Accordingly, organizations fail to allocate significant time for implementing information systems such as the FEPT. An FEPT system must provide a quick path to valuation with minimal implementation requirements. 
3) Before starting FEP, the project team must clearly communicate the need for an FEPT and other IT infrastructure and systems.

4) At the end of the FEP stage, the project managers normally conduct a gate review, called a "Project Readiness Assessment," which is an examination of all aspects of the FEP and which assures the owners in advance of project sanctioning that the project can be executed within expectations.

5) The ability of the FEPT to integrate with a full project information management system enhances its value by providing consistency throughout the project life cycle, by building a traceable relationship between the FEP and the execution deliverables, and by preventing the loss of information.

\section{CONCLUSION}

The performance of construction megaprojects can be improved with the implementation of a front-end planning (FEP) process. However, FEP is normally constrained by tight schedules and limited resources. The main deliverables of FEP are a level of design sufficient for the preparation of cost and schedule estimates that will then be used to determine authorization for project expenditures. By developing FEPT, the research team contributes to facilitate and promote current FEP practices. Using a front-end planning tool (FEPT) is helpful in increasing the efficiency and control of the FEP process that positively affect overall project performance. The FEPT presented in this paper provides rapid implementation of a solution that can accommodate a compressed schedule while supporting an enhanced level of control and quality with respect to FEP deliverables.

\section{REFERENCES}

[1] G. Briscoe, A. Dainty, S. Millett, "Construction supply chain partnerships: skills, knowledge and attitudinal requirements", European Journal of Purchasing \& Supply Management, vol. 7, no. 4, pp. 243-255, 2001.

[2] G. E. Gibson, J. H. Kaczmarowski, H. E. Lore, "Pre-project planning process for capital facilities", Journal of Construction Engineering and Management, ASCE, vol. 121, no. 3, pp. 312-318, 1995.

[3] G. Bates, "Envisioning Successful Construction: Project Planning is the Key", Journal of Management in Engineering, vol. 11, no. 4, pp. 3, 1995.

[4] C. Cheah, M. Garvin, J. Miller, "Empirical Study of Strategic Performance of Global Construction Firms", Journal of Construction Engineering and Management, ASCE, vol. 130, no. 6, pp. 808-817, 2004.

[5] C.Y.J. Cheah, D.A.S. Chew, "Dynamics of strategic management in the Chinese construction industry", Management Decision, vol. 43, no. 4, pp. 551-567, 2005.

[6] D.A Whittington, G.E. Gibson, Q. Cui, "Analysis Supporting Front End Planning for Renovation and Revamp Projects, Part 2", RR242-12, Construction Industry Institute (CII), Austin, Texas, 2009.

[7] S.M. AbouRizk, "Value for Money Audit: Project Management Cost Estimating" Report to City of Edmonton, Office of the Auditor General, 1998.
[8] M.Z.A Abd Majid, R. McCaffer, "Factors of Non-Excusable Delays that Influence Contractors'Performance", Journal of Management in Engineering, vol. 14, no. 3, pp. 42-48, 1998.

[9] S. T. Ariaratnam, C. W. MacLeod, "Financial outlay modelling for a local sewer rehabilitation strategy," Journal of Construction Engineering and Management, vol. 128, no. 6, pp. 486-495, 2002.

[10] D.N. Ford, D.M. Lander, J.J. Voyer, "A real options approach to valuing strategic flexibility in uncertain construction projects", Construction Management and Economics, vol. 20, pp. 343-351, 2002.

[11] T.R. Stacey, "Design - a strategic issue. Proc. 2nd Int. Seminar on Strategic vs Tactical Approaches in Mining, Perth, Australia", Australian Centre for Geo mechanics, Section 4, pp. 13, 2006.

[12] T. Williams, K. Samset, "Issues in Front-End Decision Making on Projects", Project Management Journal, vol. 41, no. 2, pp. 38-49, 2010.

[13] Construction Industry Institute (CII), "Break the Rules and Pay the Price", RS213-1, Construction Industry Institute (CII), Austin, Texas, 2008.

[14] G.E. Gibson, "The real value of front end planning for capital projects", FIATECH Webinar, http://fiatech.org/webinar-archives, 2010 .

[15] K. London, R. Kenley, A. Agapiou, "Theoretical Supply Chain Network Modelling in the Building Industry", 14th Annual Association of Research in Construction Management, pp. 369 379, 1998.

[16] R. Vrijhoef, L. Koskela, "The Four Roles of Supply Chain Management in Construction", European Journal of Purchasing \& Supply Management, vol. 6, pp. 169-178, 2000.

[17] J.H. Tah, "Toward an agent-based construction supply network modeling and simulation platform", Automation in Construction, vol. 14, no. 3, pp. 353-359, 2005.

[18] A. Cox, P. Ireland, M. Townsend, "Managing in Construction Supply Chains and Markets", London, United Kingdom: Thomas Telford Publishing, 2006.

[19] Construction Industry Institute (CII), "Pre-project planning handbook", SP39-2, Construction Industry Institute (CII), Austin, Texas, 1995.

[20] D.I. Cleland, L.R. Ireland, "Project management: Strategic design and implementation", New York: McGraw-Hill, 2002.

[21] A. Griffith, G. Gibson, "Alignment during pre-project planning", Journal of Management in Engineering, ASCE, vol. 17 , no. 2, pp 69-76, 2001

[22] S.K. Lee, J.H. Yu, "Critical Success Factors for Project Management Information System in Construction" Journal of Construction Engineering and Project Management, vol. 1, no. 1, pp. 25-30, 2011

[23] S. Shokri, M. Safa, C. Haas, R. Haas, "A Conceptual Framework to Improve Information and Process Management in the Execution of Capital Projects", 3rd International/9th Construction Specialty Conference, Ottawa, Ontario, 2011.

[24] B. Kidd, "Validate definitions and experiences with project stages", http://www.kentz.com/what-we-do/specialistepc/15/kentz-integrated-solutions, Tele-conference (interview), Husky Energy Inc, September 15, 2011.

[25] Tenaska Trailblazer Partners, LLC, "Final Front End Engineering and Design Study Report", Report to the Global CCS Institute, 2012.

[26] KBR Inc., "KBR Awarded FEED and Project Management Services Contract by Saudi Aramco for the Jazan Refinery and Marine Terminal Project", http://www.kbr.com/Newsroom/PressReleases/2011/02/09/KBR-Awarded-FEED-and-ProjectManagement-Services-Contract-by-Saudi-Aramco-for-the-JazanRefinery-and-Marine-Terminal-Project/, 2011.

[27] C.T. Hyun, Y.W. Cha, R.Z. Jin, M.J. Son, "Change and contract management modules of intelligent- program management information systems (i-PgMIS) for urban renewal project", Gerontechnology, vol. 11, no. 2, pp. 172-179, 2012. http://dx.doi.org/10.4017/gt.2012.11.02.419.00, 2012.

[28] Emerson Process Management, "Front End Engineering Design Capabilities", Emerson Process Management, USA, 2005.

[29] Chiyoda Corporation, "FEED (Front End Engineering Design)", http://www.chiyoda-corp.com/service/en/plant/feed.html, 2012.

[30] Bentley, "Best Practices in Front-End Design", A Bentley White Paper, www.bentley.com, 2008. 
[31] G. Stephen, W. Hughes, D. Ancell, "Risk under performance-based contracting in the UK construction sector", Construction Management \& Economics, vol. 25, no. 7, pp. 691-99, 2007.

[32] S. Konukcu, C. Anumba, P. Carrillo, "The need for knowledge chains in construction", Rotterdam (Netherlands) in-house publishing , 2008.

[33] S. Laryea, W. Hughes, "Risk and price in the bidding process of contractors", Journal of Construction Engineering and Management, ASCE, vol. 137, no. 4, pp. 248-260, 2011.

[34] K.M. Cho, T.H. Hong, C.T. Hyun, "Effect of project characteristics on project performance in construction projects based on structural equation model", Expert Systems with Applications, vol. 36, no. 7, pp. 10461-10470, 2009. 